\title{
Temperature Impact on the Shannon-Wiener Biodiversity Index (BDI) of Zooplankton in Lake Kinneret (Israel)
}

\author{
Moshe Gophen \\ MIGAL-Scientific Research Institute, Kiryat Shmona, Israel \\ Email: Gophen@Migal.org.il
}

How to cite this paper: Gophen, M. (2018) Temperature Impact on the Shannon-Wiener Biodiversity Index (BDI) of Zooplankton in Lake Kinneret (Israel). Open Journal of Modern Hydrology, 8, 39-49.

https://doi.org/10.4236/ojmh.2018.82004

Received: January 23, 2018

Accepted: April 5, 2018

Published: April 8, 2018

Copyright $\odot 2018$ by author and Scientific Research Publishing Inc. This work is licensed under the Creative Commons Attribution International License (CC BY 4.0).

http://creativecommons.org/licenses/by/4.0/

\begin{abstract}
The Shannon-Wiener Biodiversity Index was implemented for Zooplankton Diversity (BDI) in Lake Kinneret (1970-2001). It was computed based on monthly mean densities in relation to Epilimnetic temperatures. 4, 5 and 9 species of Copepoda, Cladocera and Rotifera, respectively, were included. Direct relations between Epilimnetic temperatures and Zooplankton Bio-Diversity Indexes (BDI) were indicated: Matching was found between low BDI and the high summer temperature and between higher BDI and the low winter temperature as well. Similar correspondence did not indicate annual means of BDI values. Zooplankton density and temperature probably resulted from smoothed confound of the averaged temperature changes. Conclusively, in the monomictic Lake Kinneret located in the temperate zone with a high degree of temperature fluctuation, causation of seasonal BDI fluctuations is possible. The consistence of global warming trend might, therefore, enhance the seasonality of BDI values changes with implications for water quality.
\end{abstract}

\section{Keywords}

Shannon, Index, Biodiversity, Zooplankton, Temperature, Kinneret

\section{Introduction}

The matching between temperature and Biodiversity, expressed as Biodiversity Index (BDI), was widely and worldwide investigated in ecological studies. The major consideration is in the essence of such relationships between ecological parameters. Previous studies documented temperature causation for modification of the BDI's aimed at undermining ecosystems' stability. It was indicated [1] that the effects of climate change potentially drive Biodiversity patterns. However, there is no consensus about independence between Temperature and Biodiversity. 
Wang et al. [1] [2] documented the greatest level of dependence between Biodiversity and Temperature at the extreme nutrient level, confirming the direct effect of Temperature and nutrients on Biodiversity. Consequently, future climate scenarios such as global warming could alter Biodiversity. The positive relations between temperature and species richness (Biodiversity) were widely documented [1] [2] [3] [4]. The impact of Biodiversity on ecosystem productivity [5] and relationships between Phosphorus and richness of species in lakes and rivers [6] were previously documented. A systematic review and meta-analysis on the interactions between climate and effects of habitat loss on Biodiversity [7], and the impact of nutrient enrichment on loss of Biodiversity and consequent declines in ecosystem productivity [8] are only few examples from the huge mass of documentation about the ecological impacts on Biodiversity traits in aquatic habitats. The global ecological role of aquatic conditions and the involvement of water in climate change, particularly biosphere warming, were considered by Parsons [3] and [4]. As on a global scale, the close relations between Biodiversity decline along latitude-elevation were widely documented [2] [9]. The crucial concern is the impact of climate change on the future of Biodiversity [1] [10] (and many others). The objective of the present paper is an attempt at correlating zooplankton diversity to temperature aimed at potential water quality modification. For the evaluation of this study, long-term Kinneret records of Zooplankton and Epilimnetic temperatures were analyzed. The correlations between periodical fluctuations of the "Shannon and Wiener Alpha Index of Biodiversity" (BDI) and the Kinneret Epilimnion Temperature records were analyzed.

\section{Methods}

Calculations of BDI were carried out on monthly means of zooplankton densities (No/L): Copepoda -4 species; Cladocera -5 species; Rotifera -9 species. The temperature measures were the averages of Epilimnion discrete measurements between surface and mid-Thermocline. The zooplankton and thermal data were taken from Lake Kinneret Data Base Annual Reports [11] (LKDB). To find out the potential impact of periodical duration length on the relation between BDI fluctuations and temperature, three temporal regimes were studied: 1) Annual Means during Short Period: 1970-1985; 2) Annual Means during Long Period: 1970-2001; and 3) Monthly Means values calculated for the entire period of 1970-2001.

\subsection{Statistical Methods and Result Presentation}

Statistical analyses used in this study were taken from STATA 9.1, Statistics-Data Analysis. The analyses used were: Simple linear predicted correlation and Fractional Polynomial (FP) predicted Regression. Two types of result presentations were carried out: 1) Annual and monthly line-scatter distribution sorted by years and months respectively; 2) Fractional Polynomial Regression Plots (STATA.9.) for the analysis of distribution trend of change. 


\subsection{Alpha Biodiversity Index Calculation (Young 2017)}

Alpha Index of Shannon-Wiener Biodiversity (BDI) was calculated. "Biodiversity Calculator for Simpson and Shannon Indexes" [12] was used. The BDI used in this study that was selected from Young's manipulation is Alpha Biodiversity $[\alpha]$, known as "Shannon Index" (short version) or "Shannon-Wiener Biodiversity Index" (full version) (BDI) [13] [14]. The equation for the BDI calculation is:

BDI Value is equal to:

$$
-\sum[(n i / N \times \ln (n i / N))]
$$

where:

$\boldsymbol{n i}=$ Number of specimens in each Taxonomic group; in the present case: Copepoda-4 species; Cladocera-5 species; Rotifera-9 species; Total Zooplankton-3 items, Copepoda, Cladocera, and Rotifera.

$\boldsymbol{N}=$ Total number of specimens in the entire community.

Consideration of the calculated results was as follows: the higher the BDI value is, the more the community is diverted, i.e. the richness of a specimen is higher and/or species are closest to balanced densities status. If all specimen densities are similar, the Index is highest and entirely richness-dependant. In other words, as high as the BDI value is, the community richness is higher and specimens are balanced.

\section{Results}

Results are presented in Table 1 and Table 2 and Figures 1-6: Figure 1 and Figure 2 refer to the short period (1970-1985) evaluations, and those of the longer period (1970-2001) are given in Figures 3-6. Results of Linear Regressions computations are shown in Table 1 and Table 2.

\subsection{Annual Means: 1970-1985 (Figure 1, Figure 2)}

Data shown in Figure 1 (line scatter) indicates the fairly low amplitude of annual fluctuations of the zooplankton (Copepoda, Cladocera, Rotifera) densities. Nevertheless, Fractional Polynomial Regression represents a decline of the BDI

Table 1. Simple Linear Regression (two dimensional sample variables: Independent (X) Vs dependent (Y) with resulted correlation parameters $\left(\mathrm{r}^{2}, \mathrm{p}\right)$ between epilimnetic Temperature (monthly mean) (Tem.), Time (month), Monthly means of the Index of Diversity (Index), Total zooplankton densities (No/L) (Total) during 1970-1985.

\begin{tabular}{cccc}
\hline Regression & $\mathrm{r}^{2}$ & Probability $(\mathrm{p})$ & Significance* $^{*}$ \\
\hline Tem Vs Month & 0.417 & 0.023 & $\mathrm{~S}$ \\
Index Vs Month & 0.213 & 0.131 & $\mathrm{NS}$ \\
Index Vs Tem & 0.363 & 0.038 & $\mathrm{~S}$ \\
Total Vs Tem & 0.707 & 0.0006 & $\mathrm{~S}$ \\
Total Vs Month & 0.696 & 0.0007 & $\mathrm{~S}$ \\
Total Vs Index & 0.271 & 0.083 & $\mathrm{NS}$ \\
\hline
\end{tabular}

${ }^{*} \mathrm{~S}=$ Significant $(\mathrm{p}<0.1) ; \mathrm{NS}=$ Not Significant $(\mathrm{p}>0.1)$. 
Table 2. Linear Regression parameters $\left(\mathrm{r}^{2}, \mathrm{p}\right)$ between epilimnetic Temperature (annual mean) (Tem.), Time (year), Annual mean Index of Diversity (Index), annual mean of Total zooplankton densities (No/L) (Total) during 1970-2001.

\begin{tabular}{cccc}
\hline Regression & $\mathrm{r}^{2}$ & Probability $(\mathrm{p})$ & Significance* $^{*}$ \\
\hline Tem Vs Year & 0.307 & 0.001 & $\mathrm{~S}$ \\
Index Vs Year & 0.525 & $<0.0001$ & $\mathrm{~S}$ \\
Index Vs Tem & 0.180 & 0.015 & $\mathrm{~S}$ \\
Total Vs Tem & 0.007 & 0.642 & $\mathrm{NS}$ \\
Total Vs Year & 0.141 & 0.034 & $\mathrm{~S}$ \\
Total Vs Index & 0.272 & 0.002 & $\mathrm{~S}$ \\
\hline
\end{tabular}

${ }^{*} \mathrm{~S}=$ Significant $(\mathrm{p}<0.1) ; \mathrm{NS}=$ Not Significant $(\mathrm{p}>0.1)$.

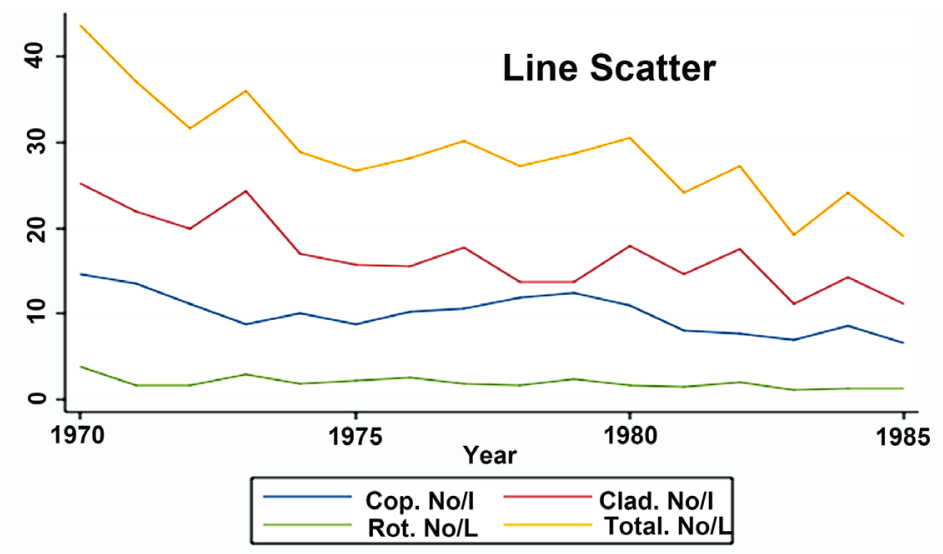

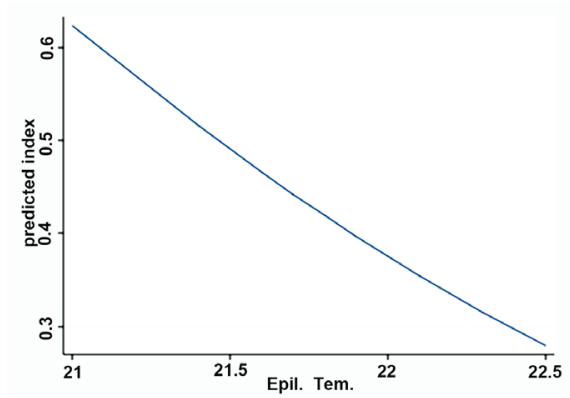

Copepoda: BDI Vs. Epil.Tem, 1970-1985 Annual Means

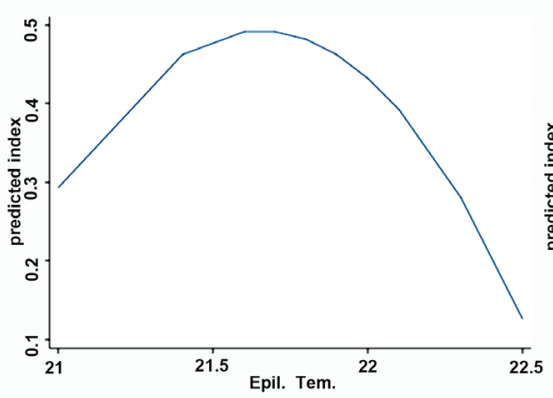

Cladocera: BDI Vs. Epil.Tem, FP; 1970-1985 Annual Means

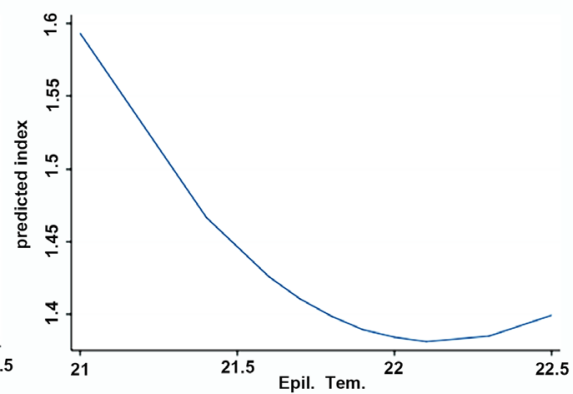

Rotifera: BDI Vs. Epil.Tem, FP; 1970-1985 Annual Means

Figure 1. Line scatter (upper panel) of Zooplankton (Copepoda, Cladocra, Rotifera) mean annual densities (No./L); Lower panel: BDI (Copepoda, Cladocera, Rotifera) FP regression Vs Epilimnetic Temperature (1970-1985).

values with Temperature increase for the three zooplankton groups. Consolidations of these trends of changes are given in Figure 2 where an increase of total zooplankton densities was accompanied by the decline of BDI. The decrease of total zooplankton densities in time (years) occurs as well (Figure 2).

\subsection{Annual Mean: 1970-2001 (Figure 3)}

Data shown in Figure 3 refer to annual means of BDI and temperature. It is indicated that: 1) There is a close similarity between annual average densities of 

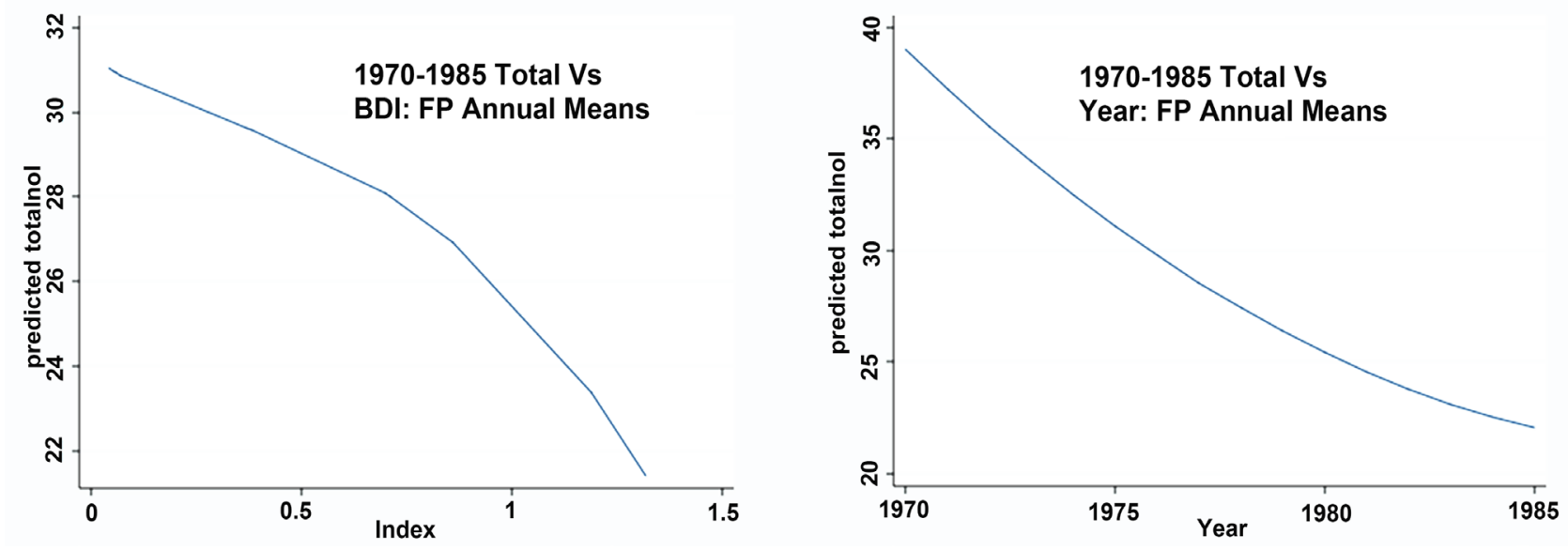

Figure 2. FP regressions of Annual Means of Total zooplankton densities (No/L) Vs BDI (left panel) and Years (1970-1985) (right panel).
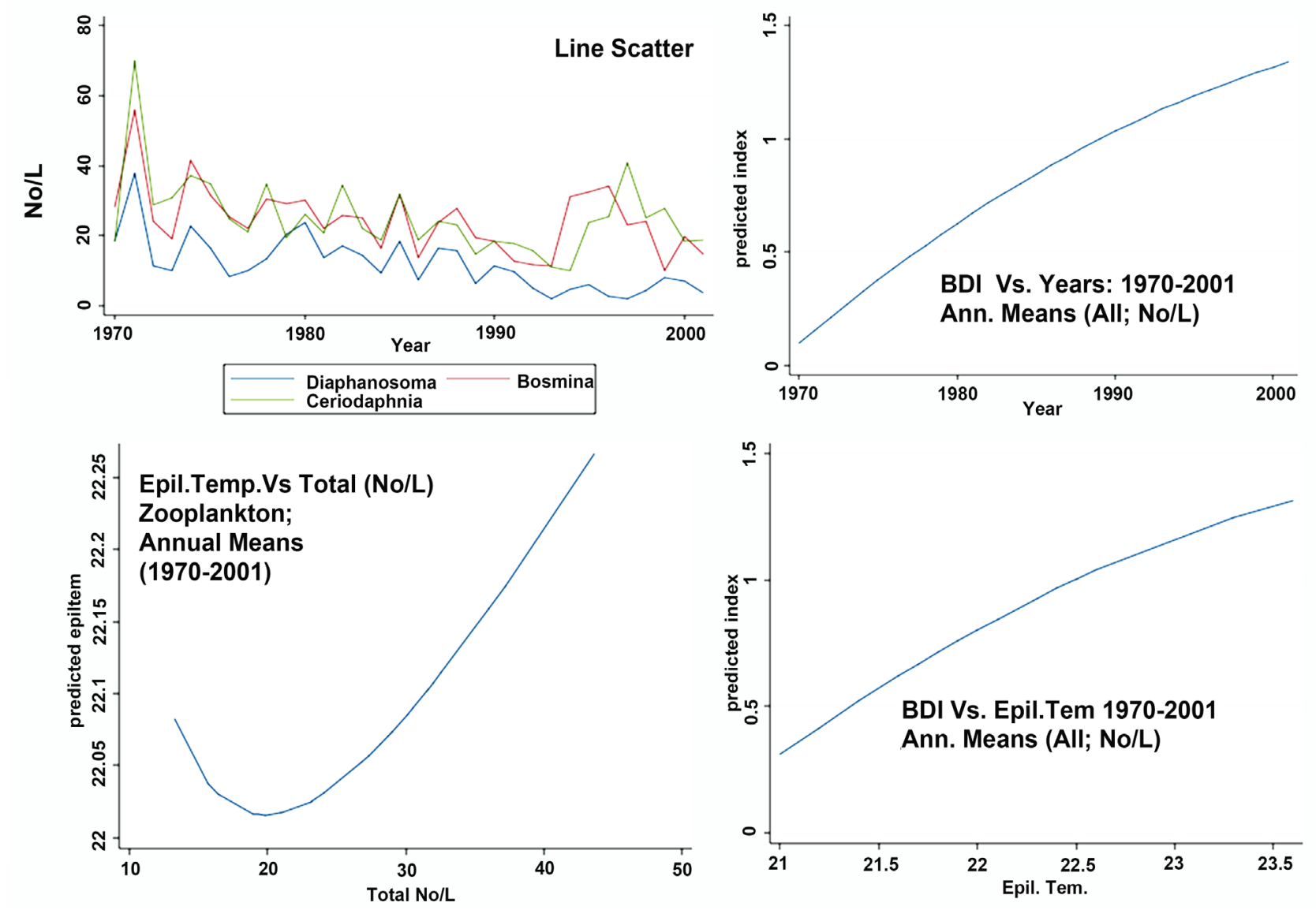

Figure 3. Line scatter of annual mean densities (No./L) Cladocerans (Diaphanosoma, Bosmina, Ceriodaphnia) Vs Years (1970-2001) And FP regressions between BDI Vs Epilimnetic mean tempoeratures and Years (1970-2001) and, Epilimnetic mean temperatures Vs Total Zooplankton Annual densities.

the three species of Cladocera (Line Scatter); 2) The Fractional Polynomial Regression plots indicate an increase of BDI with time (Years) and with minor $\left(21^{\circ} \mathrm{C}-23.5^{\circ} \mathrm{C}\right)$ changes in annual means of temperature. 


\subsection{Monthly Means: 1970-2001 (Figures 4-6)}

Data shown in Figures 4-6 refer to monthly means during the long-term period of 1970-2001. In Figure 4 the decline of BDI with Temperature increase $\left(18^{\circ} \mathrm{C}\right.$ $28^{\circ} \mathrm{C}$ ) and with total zooplankton densities is shown. The inverse relation between temperature (monthly means averaged for 1970-2001) of the Epilimnion and the BDI is clearly indicated in Figure 5. Figure 6 represents the inverse relation between zooplankton densities (Copepoda, Cladocera, Rotifera and obviously Total) and month based on monthly means averaged for 1970-2001. The data record for all figures and tables is the same. The difference is due to the time fragmentation and the respective mean values: annually for short (1970-1985) and longer (1970-2001) periods and monthly for the period of 1970-2001. The dissimilarity of BDI values for annual or monthly duration fragments of short (1970-1985) and longer (1970-2001) periods was confirmed.

\section{Discussion}

The BDI is a measure of biological diversity which is commonly used in the ecological sciences. This index is an indicator of species richness in a habitat diverted at the Anthropy Term from the informatical theory developed by Shannon [13] [14]. The usage of BDI and other closely related indexes is known worldwide. Among common ecological investigations of Biodiversity, the geographical change of BDI value with respect to latitude is widely known [15]. It was fairly accepted that the dominant parameter effect on the BDI changes is temperature. Global Biodiversity expressed as the richness of families, genera, species and sub-species is significantly affected by temperature [15]. The decline of $\mathrm{BDI}$ in response to warm "greenhouse" phases which may have implications for biological extinctions and Biodiversity changes under future global warming events is also known [15]. An old question was recently addressed by Stephen-Dewenter et al. [16]: Why are the tropics home to more species than higher latitudes? The cardinal part of the response that Biodiversity is driven by
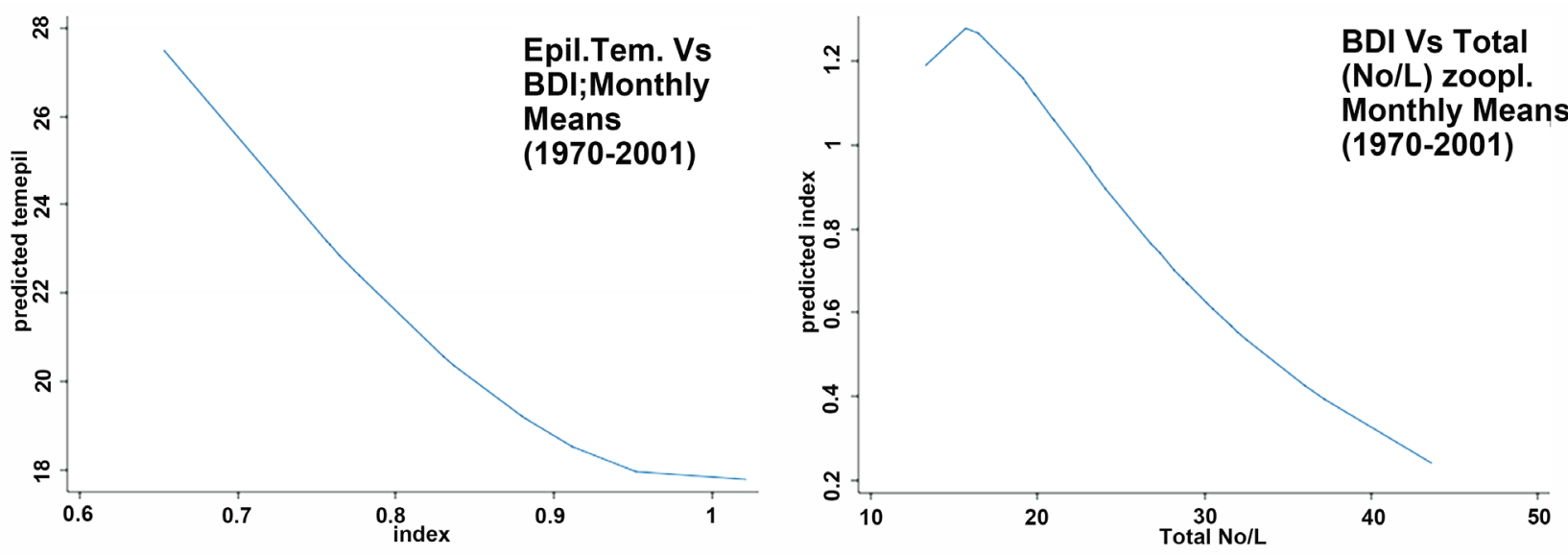

Figure 4. FP regressions between Monthly averages of BDI and Total Zooplankton densities and Epilimnetic monthly means during 1970-2001. 

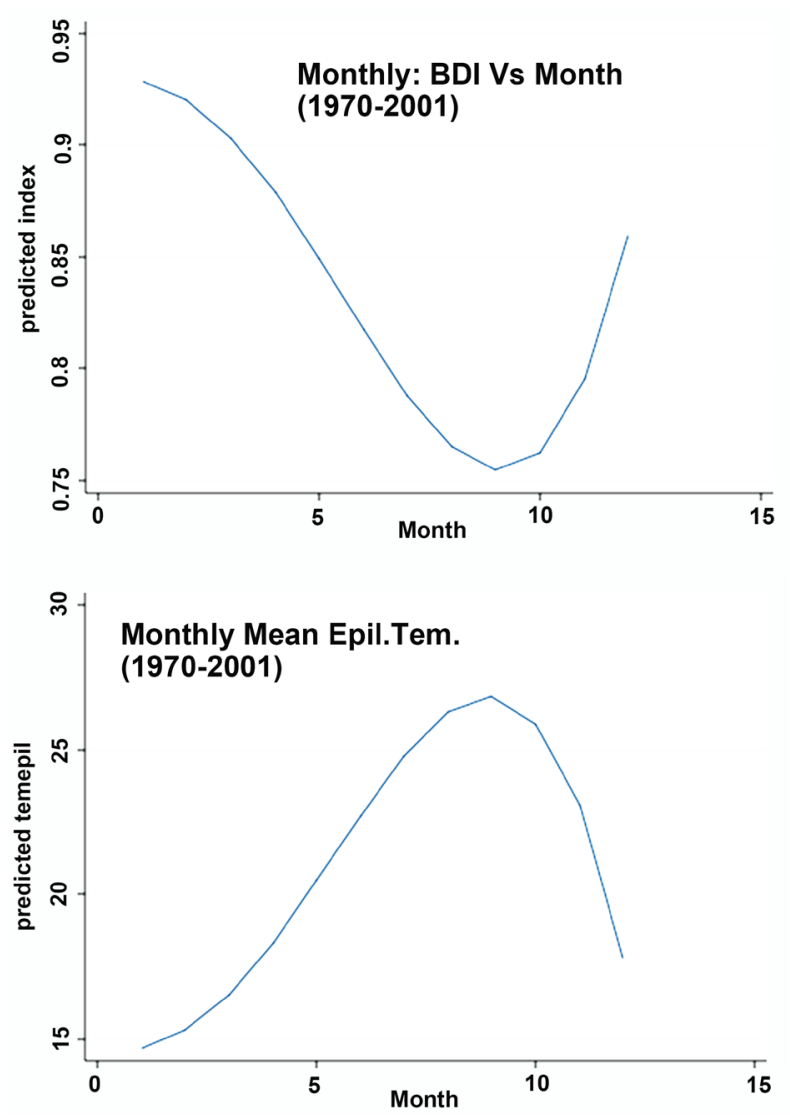

Figure 5. Monthly means of epilimnetic temperatures (lower panel and monthly means of BDI Vs month (1970-2002)).

temperature convinced the publisher of Science to declare it to be one of the 25 most important questions of science to be answered yet [16] [17]. It is likely that those scientific suggestions support a significant justification for the present study. The evaluation of temporal changes in temperature impact on Biodiversity of similar taxonomical compositions during seasonal and annual timing regime is the essence of the present study. The global fluctuations of Biodiversity over a long-term era $\left(540 \times 10^{6}\right.$ year) was indicated [18]. The fossil study of geographic distribution of life pattern on Earth supported a clear mode of Biodiversity increase with increasing temperature. Long-term (million years) changes of Biodiversity and decline of Biodiversity in high latitudes are well-known. Nevertheless, the temporal changes of Biodiversity along short periods (annual and seasonal) within the same body of water and similar taxonomical compositions were less studied. A principal conclusion in the UN report on loss of Biodiversity and extinctions [19] is that the severe threat to species richness and elimination is significantly affected by climate change. The global warming trend has an impact on the rate of Biodiversity not being reduced [20]. Hoffman [21] indicated that, among others, climate change is affecting habitats by forcing species migration as they look for more favorable conditions or die. Even small changes of averaged temperature may have a significant effect upon ecosystems [21]. An 

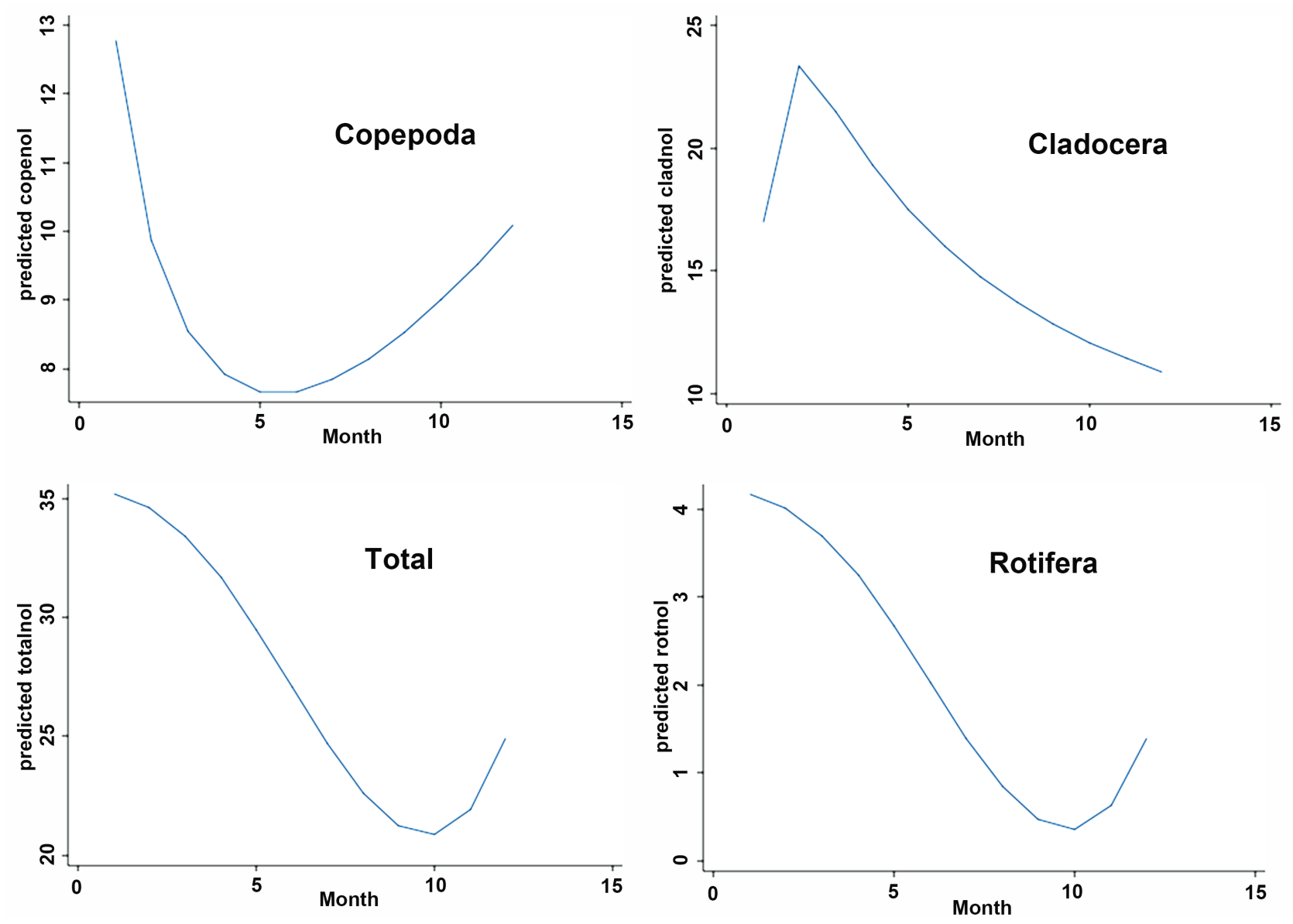

Figure 6. Monthly Means (1969-2001) (No/L) of zooplankton groups (Copepoda, Cladocera, Rotifera, Total) densoties Vs Month.

international objective aimed at reduction of the current rate of Biodiversity loss was defined [20] but considered as not met. This UN Outlook 3 Report (Biodiversity 2010) concluded there are several challenges to reducing the rate of Biodiversity decline. Three levels of international efforts were defined: genetics, species and ecosystem. This report [20] emphasizes the existence of constant or even increasing pressure of climate change driving Biodiversity loss. The impact of climate change on Biodiversity depends on the adaptive ability of species. When stable climate conditions are disrupted, the only options for species such as aquatic zooplankton are to adapt or die.

When temporal changes of BDI are evaluated against short-time regimes as monthly or short annual trait (Figure 1, Figure 2, Figures 4-6), the decline of the index is clearly related to temperature elevation. Consequently, an indication of the effect of global warming on BDI decline is essential. Nevertheless, the significance of such an indication may be justified only when thermal change is higher than the $1^{\circ} \mathrm{C}-2^{\circ} \mathrm{C}$ regime. If the thermal range is minor, its impact on BDI is not essential. Similarly, if the minor thermal change continues during the long period, BDI stays consistent and modified if time range is short. Conclusively, BDI is affected by temperature but the significance of this impact depends on the time span continuation and/or the thermal range of the modification. The 
question to be answered is: are these relations between Temperature and BDI not more than arithmetic evaluation or ecological consequences and are they justified? It is suggested that the high thermal range evaluation together with short periodical annual considerations support the ecological attitude confirmation. Data shown in Table 1 and Table 2 indicates linear relations between all the monthly parameters of Temperature, BDI and Total Zooplankton during the 16-year period (1970-1985) as well as during the longer (31 years) period (1970-2001). Nevertheless, dissimilarity of the trend of changes (FP, Figure 3) was indicated between those evaluations: During 16 years the BDI declined with temperature increase, and during 31 years the trend was the opposite: BDI increased with temperature elevation based on annual means and decline when based on monthly averages. Conclusively, the long period (31 years) analysis with respect to minor $\left(1^{\circ} \mathrm{C}-2^{\circ} \mathrm{C}\right)$ changes of temperature resulted in BDI increase which is the opposite as in a shorter period (16 years) and/or monthly means. Consequently, the usage of monthly means was preferred for the analysis.

Two optional datasets were suggested tentatively as an attempt to analyze BDI modifications: monthly or annually. The monthly option represents an amplitude of $10^{\circ} \mathrm{C}-12^{\circ} \mathrm{C}$ and annual averages only $-1^{\circ} \mathrm{C}-3^{\circ} \mathrm{C}$ respectively. The usage of annual means is applicable to two options: short and long periods (16 and 31 years here). Results presented in Figures 1-3 represent supposedly controversy: decline of BDI during 1970-1985 whilst increase of BDI during 1970-2001. It is suggested that this inverse results is due to the lower thermal fluctuated amplitude based on longer term period. The chance for an indication of high thermal amplitude in the shorter period is better since averaged smoothing is avoided. Consequently, the relation between BDI and annual means of temperature is better pronounced whilst the usage of low amplitude $\left(2^{\circ} \mathrm{C}-3^{\circ} \mathrm{C}\right)$ means to confound the real greater changes. The higher BDI in the tropics is a known case! It is suggested that it is not due solely to the high temperature there but to the combination of it and the thermal conditions' continuity. If high and low thermal conditions alternate, BDI fluctuates intermittently as well. It is questioned why low BDI is correlated with high temperature and vice versa (Figure 5 and Figure 6). Moreover, long-term data record of zooplankton distribution clearly indicates high biomass in winter months and low biomass in summer [11]. The reason for that is the direct relation between temperature and metabolic expenses and the survival of zooplankton organisms. The metabolic cost in summer is significantly higher than in winter [22]. The short time duration of intensive metabolism of aquatic invertebrate organisms under high thermal regime initiates entire life stages activity at lower metabolic efficiency and shorter overturn time of the entire population and therefore leads towards a reduction of diversity and lower BDI. Organisms that cannot be retained are seasonally and partly eliminated and reappear in full capacity when temperature declines. The high-temperature status of life metabolism is constantly high in the tropics and, therefore, the evolutionary/genetic mechanism of speciation is causing high BDI 
continuity at a faster and more efficient rate. That is why monthly means are more suitable than annual averages for BDI fluctuations analysis in temperate ecosystems such as stably stratified Lake Kinneret where winter-summer water temperature difference varied between $11^{\circ} \mathrm{C}$ and $15^{\circ} \mathrm{C}$.

\section{Conclusive Summary}

Global Warming is of interest worldwide since its impact is related to the whole planet. The Warming effect has several implications with a significant effect on human beings in all aspects of life. Nevertheless, the expression of warming impact is sometimes very pronounced and sometimes less. This paper has considered the less pronounced expressions. It is done by evaluation of the BDI regime of the aquatic invertebrate organisms, copepods, cladocerans and rotifers of Lake Kinneret. It was indicated that seasonal fluctuations of epilimnetic temperature are consequently accompanied by a significant change of BDI level. Therefore, it is concluded that BDI monitoring in the Kinneret Epilimnion supports an indication of Global Warming effect in this part of the planet. The study of the BDI fluctuations is, therefore, significant towards awareness about its negative implications on water quality.

\section{References}

[1] Wang, J., Pan, F., Soinien, J., Heino, J. and Shen, J. (2016) Nutrient Enrichment Modifies Temperature-Biodiversity Relationships in Large-Scale Field Experiments. Nature Communications, 7, Article Number: 13960.

[2] Wang, J., et al. (2017) Regional and Global Eleventional Patterns of Microbial Species Richness and Evenness. Ecography, 40, 393-402.

[3] Parsons, M.L. (1995) Forward, Preface, Water. In: Global Warming, The Truth and the Myth, Insight Books, Plenum Press, New York and London, 189-211.

[4] Sweney, B.W., Jackson, J.K., Newbold, J.D. and Funk, D.H. (1992) Climate Change and the Life Stories and Biogeography of Aquatic Insects in Eastern North America. In: Firth and Fisher, Eds., Global Climate Change and Freshwater Ecosystems, Springer-Verlag, New York, Berlin, Heidelberg, London, Tokyo, Hong Kong, Barcelona, Budapest, 143-176.

[5] Tilman, D., Reich, P.B. and Isbell, F. (2012) Biodiversity Impacts Ecosystem Productivity as Much as Resources, Disturbance, or Herbivory. Proceedings of the National Academy of Sciences of the United States of America, 109, 10394-10397.

[6] Azevedo, L.B., et al. (2013) Species Richness-Phosphorus Reletionships for Lakes and Streams Worldwide. Global Ecology and Biogeography, 22, 1304-1314.

https://doi.org/10.1111/geb.12080

[7] Mantyka-Pringle, C.S., Martin, T.G. qnd Rhodes, J.R. (2012) Interactions between Climate and Habitat Loss Effects on Biodiversity: A Systematic Review and Beta-Analysis. Global Ecology and Biogeography, 18, 1239-1252. https://doi.org/10.1111/j.1365-2486.2011.02593.x

[8] Isbell, F., et al. (2013) Nutrient Enrichment, Biodiversity Loss, and Consequent Declines in Ecosystem Productivity. Proceedings of the National Academy of Sciences of the United States of America, 110, 11911-11916.

https://doi.org/10.1073/pnas.1310880110 
[9] Quian, H. and Ricklef, R.E. (2007) Latitudnal Gradient in Large-Scale Beta Diversity for Vascular Plants in North America. Ecology Letters, 10, 737-744. https://doi.org/10.1111/j.1461-0248.2007.01066.x

[10] Bellard, C., Bertesmeier, C., Leadley, P., Thuiller, W. and Courchamp, P. (2012) Impacts of Climate Change on the Future of Biodiversity. Ecology Letters, 15, 365-377. https://doi.org/10.1111/j.1461-0248.2011.01736.x

[11] (1970-2001) KLL-IOLR LKDB Annual Reports.

[12] Young, T.M. (2017) Biodiversity Calculator for the Simpson and Shannon Indexes. Copyright 2017 by Tanner, M., Young All Rights Reserved, Page Loaded 14 Days Ago, Formula and Manual for the Calculation of Shannon-Wiener Index Alpha Biodiversity [ạ], 4 p. https://www.alyoung.com/labs/biodiversity_calculator.html

[13] Tuomisto, H. (2010) A Consistent Terminology for Quantificatifying Species Diversity? Yes, It Does Exist. Oecologia, 4, 853-860. https://doi.org/10.1007/s00442-010-1812-0

[14] Shannon, C.E. (1948) A Mathematical Theory of Communication. The Bell System Technical Journal, 27, 379-423. https://doi.org/10.1002/j.1538-7305.1948.tb01338.x

[15] Mayhew, P.J., Jenkins, G.B. and Benton, T.G. (2008) A Long-Term Association between Global Temperature and Biodiversity, Origination and Extinction in the Fossil Record. Proceedings of the Royal Society B: Biological Sciences, 275, 47-53.

[16] Stephen-Dewenter, I., Detsch, F., Classen, A., et al. (2016) Predictors of Elevational Biodiversity Gradients Change from Single Taxa to the Multi-Taxa Community Level. Nature Communications, 7, Article No. 13736. https://doi.org/10.1038/ncomms13736

[17] Stephen-Dewenter, I. (2016) Temperature Drives Biodiversity. Science Daily, University of Wurzburg.

[18] Mayhew, P.J., Bell, M.A., Benton, T.G. and McGowan, A.J. (2012) Biodiversity Tracks Temperature over Time. Proceedings of the National Academy of Sciences of the United States of America, 109, 15141-15145. https://doi.org/10.1073/pnas.1200844109

[19] Shah, A. (2014) Loss of Biodiversity and Extinctions. Last Updated Sunday, 19 January 2014, Global Issus.

http://www.globalissues.org/article/171/loss-of-biodiversity-and-extinctions Print: http://www.globalissues.org/print/article/171

[20] Global Biodiversity Outlook 3 (GBO 3). Biodiversity in 2010, Final Report Executive Summary 2010, Convention on Biological Biodiversity, UN-Environment, 5 p. https://www.cbd.int./gbo/?pub=6667\&section $=6673$

[21] Hoffman, A. and FAA (Expert Reviewer) (2017) Curious-Climate Change and Biodiversity, Curious 101 Australian Academy of Science Newsletter.

[22] Gophen, M. and Azoulay, B. (2002) The Trophic Status of Zooplankton Communities in Lake Kinneret (Israel). Internationale Vereinigung für Theoretische und Angewandte Limnologie: Verhandlungen, 28, 836-839. https://doi.org/10.1080/03680770.2001.11901831 